TITLE: Effects of Processing Parameters on the laser Deposition of High Temperature Superconducting Thin Films

AUthor(S): N. S. Nogar, R. Castain, R. C. Dye, S. Foltyn, R. E. Muenchausen, and $X . D$. Wu

SUBMITTED TO: Materials Research Society Meeting, November 26-30, 1990, Boston, MA

\title{
DISCLAIMER
}

This report was prepared as an account of work sponsored by an agency of the United States Government. Neither the United States Government nor any agency thereof, nor any of their exployees, makes any warranty, express or implied, or assumes any legal liability or responsibility for the accuracy, completeness, or usefulness of any information, apparatus, product, or process disclosed, or represents that its use would not infringe privately owned rights. Reference herein to any specific commercial product, process, or service by trade name, trademark, manufacturer or otherwise does not necessarily constitu.. or imply its endorsement, recommendation, or favoring by the United States Government or any agency thereof. The views and opinions fauthors expressed herein do not necessarily state or reflect those of the United State" jovernment or any agency thereof.

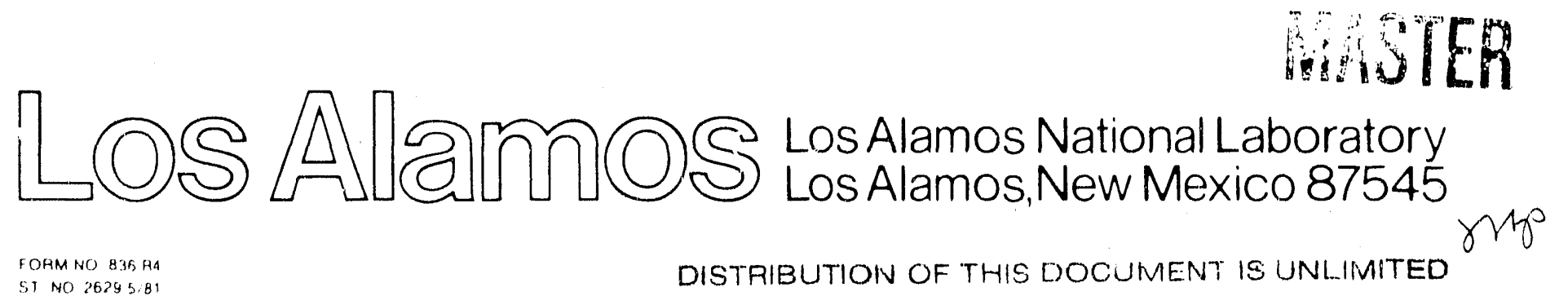




\section{EFFECTS OF PROCESSING PARAMETERS ON THE LASER DEPOSITION OF HIGH TEMPERATURE SUPERCONDUCTING THIN FILMS}

N. S. Nogara, R. Castaina, R. C. Dyea, S. Foltyna, R. E. Muenchausenb and X. D. Wub aChemical and Laser Sciences Division, MS G738

bExploratory Research and Development Center, MS K778

Los Alamos National Laboratory, Los Alamos, New Mexico 87545

ABSTRACT:

$\mathrm{Y}_{2} \mathrm{O}_{3}$ pressed powders were ablated by pulses from a XeCl excimer laser, operating at $308 \mathrm{~nm}, 150 \mathrm{~mJ} /$ pulse, $\approx 15 \mathrm{nsec} /$ pulse and $20 \mathrm{~Hz}$. Emission spectra from $Y^{*}$ and $Y O^{*}$ were recorded as a function of ambient oxygen pressure in the range $10^{-5}$ - $4 \times 10^{-1}$ Torr, at a laser fluence of $\approx 4 \mathrm{~J} / \mathrm{cm}^{2}$. A kinetic model is developed to describe the results, and the application to production of laser-deposited hightemperature superconductor thin films is discussed.

\section{INTRODUCTION:}

Laser ablation for the deposition of thin films is becoming a widely used technology. This process has some advantages relative to conventional deposition technologies $[1,2]$ including rapid growth rates, the ability to congruently evaporate multicomponent targets, and the production of high-energy $(\theta \mathrm{V})$ atoms, molecules, ions and clusters which enhance the production of epitaxial films. Laser ablation has been used most recently for the production of high-temperature superconducting (HTSC) thin films [3-5].

Recent work in this laboratory has demonstrated the production of high-quality epitaxial HTSC thin films using the laser deposition technique [6-8]. In this process, a pressed oxide target, containing a stoichiometric mixture of yttrium, barium and copper is ablated at fluences $\approx 4 \mathrm{~J} / \mathrm{cm}^{2}$. The vaporized material passes through a lowpressure oxygen atmosphere, 0.2 Torr, and is subsequently deposited on a heated $\left(700^{\circ} \mathrm{C}\right)$ substrate. The film is cooled in a relatively high-pressure oxygen atmosphere, 200 Torr.

Despite efforts to understand the chemistry of this process [9], little is known about the gas phase or surface chemistry occuring during the deposition process. In an effort to elucidate the mechanisms for the gas phase chemistry, we have undertaken a study of single-component metal and metal oxide laser ablation. In this work, we report on the ablation of $\mathrm{Y}_{2} \mathrm{O}_{3}$, with a XeCl excimer laser.

\section{EXPERIMENTAL:}

Tha bulk of the apparatus has been described previously [6] . Briefly, the deposition chamber consists of a modified six way $6^{n}$ dia. stainless steel cross, as shown in Figure 1. Load locks are provided for target and substrate introduction to minimize pumping times. The target can be rotated in conjunction with horizontal 
rastering of the laser beam while the substrate is rotated to ensure uniform thickness $( \pm 10 \%)$ across the substrate diameter. Provisions are made to heat the substrate, either indirectly on a Ni block or radiatively. Processing gases can be introduced into the deposition chamber using mass flow control to maintain a constant pressure or by a pulsed valve. The excimer laser used in these experiments produced $200 \mathrm{~mJ}, 20$ nsec pulses at $308 \mathrm{~nm}$ and a repetition rate of $20 \mathrm{~Hz}$.



Figure 1. Schematic of the experimetnal apparatus. Symbols: $A$, aperture; $M$, mirror; $L$, lens; FOC, fiber optic cable; CCD, charge-coupled device; T, target; S, substrate; VM, video monitor.

Additionally, for the experiments described here, the plume optical emission was collected and analyzed. Light was collected by a $7.5 \mathrm{~cm}$. diameter, $500 \mathrm{~cm}$ focal length quartz lens, and focussed onto either a photodiode or the end of a (200 $\mu \mathrm{m}$ diameter) multi-mode fiber optic cable (FOC), $10 \mathrm{~m}$ in length. The photodiode was used for total intensity measurements. The distal end of the fiber optic cable was coupled to an $0.5 \mathrm{~m}$ monochromator equipped with a gated, intensified CCD camera for spectrally resolved detection.

\section{RESULTS AND DISCUSSION:}

In previous experiments [9] , the plume resulting from ablation of a stoichiometric $\mathrm{Y}$-Ba-Cu-O target was sampled mass spectrometrically . In these experiments, gas-phase $\mathrm{Cu}, \mathrm{Cu}_{2}, \mathrm{Ba}$, and $\mathrm{Y}$ were detected, along with minor amounts of $\mathrm{BaO}$, and their velocity distributions characterized. It is interesting that in this experiment, where the solid material was ablated into a vacuum, few oxide species were detected, suggesting that the oxygen incorporated into the HTSC thin films during the laser deposition process originates in the processing atmosphere, rather than in the solid 
target material. In order to explore this hypothesis further, we have obtained data on chemical speciation under processing conditions: that is, oxygen pressures from 0.001 to 0.4 torr.

Emission spectra were obtained from the plume in the spectral region near $600 \mathrm{~nm}$, where both atomic yttrium emission $\left(\mathrm{Y}^{*}\right)$ and yttrium monoxide emission (YO*) could be observed. Figure 2 displays a spectrum obtained at an oxygen pressure of $2 \times 10^{-1}$ torr. The detector was gated to integrate signal for the duration of the emission pulse, $\approx 10 \mu \mathrm{sec}$. The two starred transitions in Fig. 2 correspond to $Y^{*}$, while most of the remaining features are due to $Y^{*}$. The $Y^{*}$ emissions are from the ${ }^{2} D_{1 / 2}$ and ${ }^{2} D_{3 / 2}$ states to the ${ }^{2} D_{3 / 2}$ ground electronic state, while the $Y O^{*}$ emission is from the $A^{2} \Pi_{3 / 2.1 / 2}$ levels to the $2 \Sigma^{+}$ground state $[11,12]$. All YO* features are due to $v^{\prime}=v^{\prime \prime}$ transitions, with the 0-0 transition being the most intense, 1-1 less intense, etc.

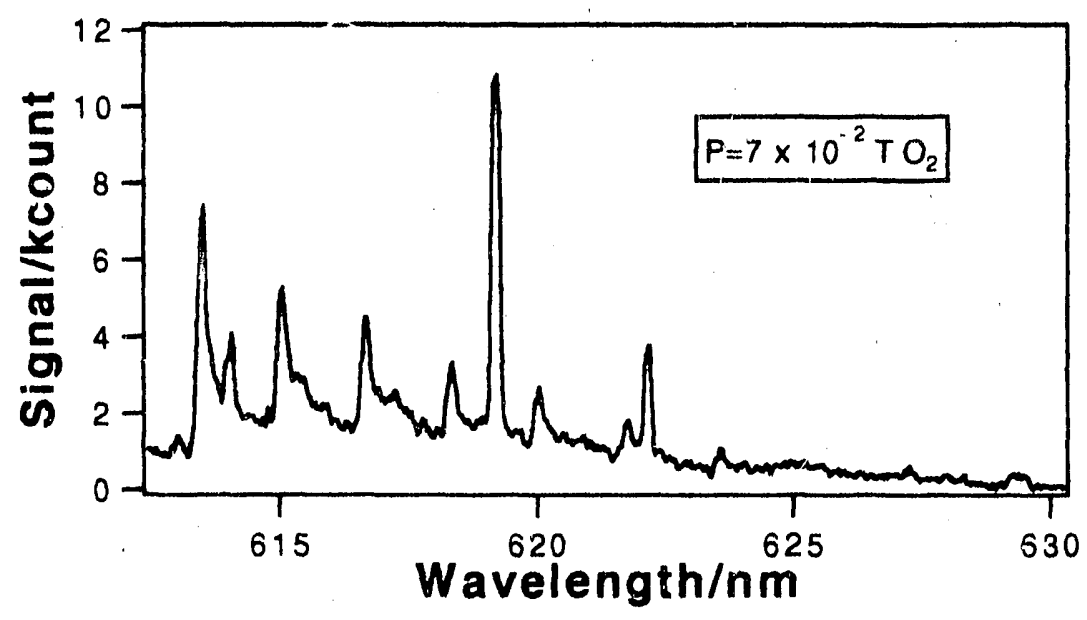

Figure 2. Emssion spectrum from interaction of material ablated from $\mathrm{Y}_{2} \mathrm{O}_{3}$ target with $7 \times 10^{-2}$ torr of $\mathrm{O}_{2}$.

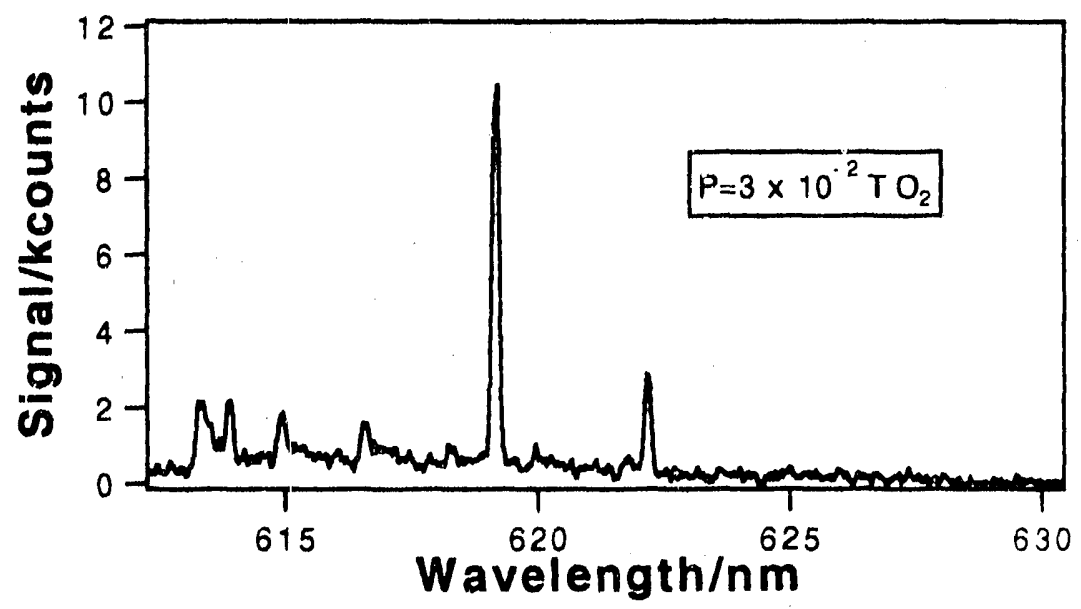

Figure 3. Emssion spectrum from interaction of material ablated from $\mathrm{Y}_{2} \mathrm{O}_{3}$ target with $3 \times 10^{-2}$ torr of $\mathrm{O}_{2}$. 
The ratio of YO* to $Y^{*}$ emission was found to change dramatically with pressure of the ambient oxygen atmosphere. Figure 3 shows a spectrum similar to Fig 2, but obtained at an oxygen pressure of $3 \times 10^{-2}$ torr. It can be seen that the emission due to $Y O^{*}$ is dramatically reduced, relative to the spectrum in Fig. 2 . In general, it was observed that the ratio $\mathrm{YO}^{*} \gamma^{*}$ increased linearly with pressure at low oxygen pressures, and approached a limiting value at pressures $\geq 0.4$ torr. No YO* emission was observed at oxygen pressures less than $10^{-3}$ torr, indicating that $\mathrm{YO}^{*}$ is not formed directly from the solid material.

In order to interpret these results, a kinetic model was developed, based on the following sequence of six reactions:

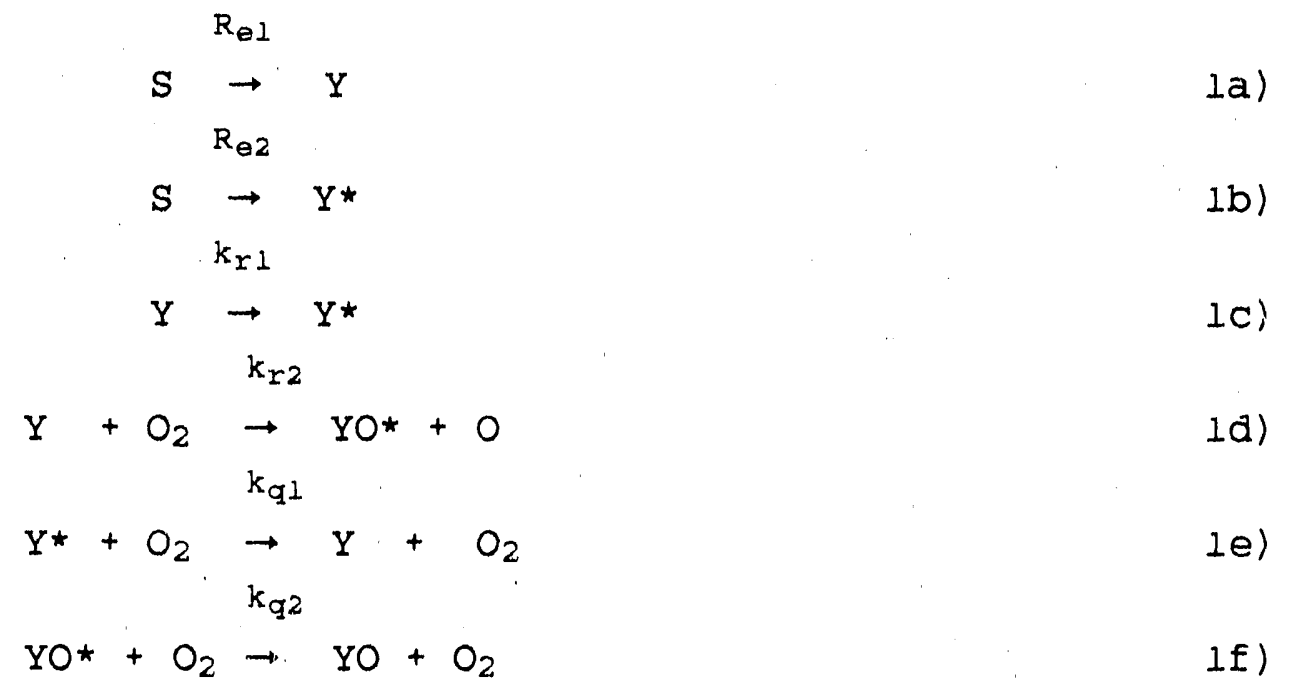

Here, $S$ indicates the solid target, $Y$ and $Y O$ are gas-phase atoms and molecules, the symbol " $*$ " indicates electronic excitation, and the R's and k's are rates and rate constants, respectively, for the indicated processes. Applying the steady-state approximation to this set of reactions results in a set of three coupled differential equations relating $Y, Y^{*}$, and $Y O^{*}$. These equations can be solved for the ratio of emission intensities. The result is shown in simplified form below:

$$
\frac{\left[\mathrm{YO}^{*}\right]}{\left.\mathrm{Y}^{*}\right]}=\frac{\mathrm{A}\left[\mathrm{O}_{2}\right]}{\mathrm{B}+\mathrm{C}\left[\mathrm{O}_{2}\right]}
$$

where the constants $A, B$, and $C$ are sums of products of the rates and rate constants, and $\left[\mathrm{O}_{2}\right]$ represents the oxygeri pressure. This result clearly obeys the correct limiting forms. At zero pressure, $\left[\mathrm{YO}^{*}\right] /\left[\mathrm{Y}^{*}\right] \rightarrow 0$, at low pressure $\left.\left[\mathrm{YO} \mathrm{O}^{*}\right] / \mathrm{Y}^{*}\right] \propto(\mathrm{A} / \mathrm{B})\left[\mathrm{O}_{2}\right]$, and at high pressure, $\left.\left[\mathrm{YO}^{*}\right] / \mathrm{Y}^{*}\right] \propto(\mathrm{A} / \mathrm{C})=$ constant.

In addition, we have demonstrated [10] an excellent fit of equation 2) to the experimental data over the entire experimental pressure range $\left(10^{-3}-0.4\right.$ torr), for a 
In addition, we have demonstrated [10] an excellent fit of equation 2) to the experimental data over the entire experimental pressure range (10-3 -0.4 torr), for a temperature $\approx 2000 \mathrm{~K}$ (see below). In this calculation, we assumed formation rates constants $R_{\theta 1}=R_{\theta 2} \approx 1 \times 10^{20}$ molec/ $/ \mathrm{cm}^{3}$-sec, resulting from the ablation of $10 \mathrm{ng}$ of material during a $100 \mathrm{nsec}$ surface thermal transient, into a volume of $\approx 10 \mathrm{~cm}^{3}$. Rate constants $\mathrm{k}_{\mathrm{r} 2}$ and $\mathrm{k}_{\mathrm{q} 2}$ are known from the literature $[12,13]$ to be $2 \times 10^{-9} \mathrm{~cm} / 1 / \mathrm{molec}$ sec. The unknown constants $k_{r 1}$ and $k_{\mathrm{q} 1}$ were allowed to vary to produce the best fit to the experimental data; best-fit values were $k_{r 1}=3 \times 10^{7} \mathrm{sec}^{-1}$ (this reaction is assumed to be pseudo-first-order, with the transition effected primarily by electrons present in the laser generated plasma) and $k_{q 1}=3 \times 10^{-9} \mathrm{~cm} 3 / \mathrm{molec}-\mathrm{sec}$.

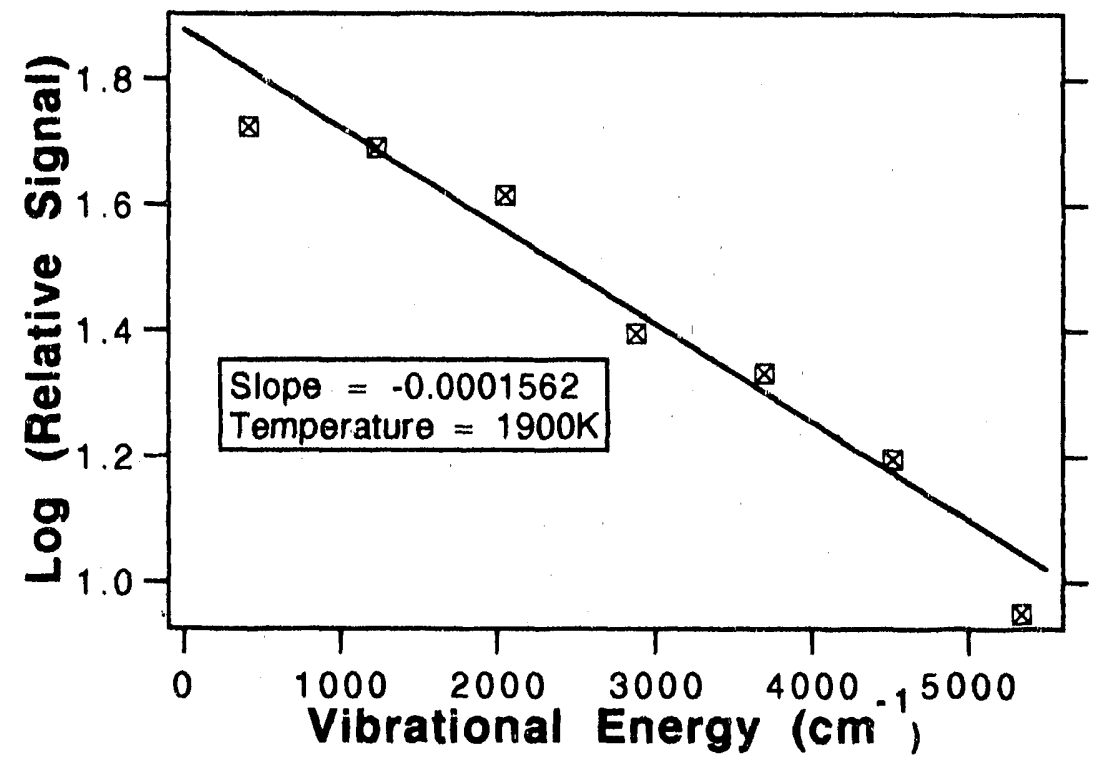

Figure 4. Determination of the vibrational temperature. The slope of this plot yields an effective temperature for the vibrational manifold.

In order to further characterize the plume chemistry and dynamics, the YO* vibrational temperature was obtained from the vibrational progression seen in Fig 2). The results are shown in Fig. 4), where the Log(intensity) for each vibrational transition is plotted against the energy for that particular vibrational level. The intensity of each transition is assumed proportional to the peak height, and peak heights are not corrected for line strength, since the Franck-Condon factors for all $v^{\prime}=v^{\prime \prime}$ transitions in YO* are near unity. The slope of this pht yields an effective temperature for the vibrational manifold of $\approx 2000 \mathrm{~K}$.

\section{CONCLUSIONS}

These resuits, together with out earlier observations, confirm that the principal source for oxygen incorporated into laser-deposited HTSC thin films is the processing atmosphere, rather than oxygen in the target material. This has been confirmed both by mass spectrometry, and by the current experiments in emission spectroscopy. 
Clearly, the absence of any $\mathrm{YO}^{*}$ at low oxygen pressures indicates that direct production of YO* from the solid is a low-probability process, while the observation of $Y^{\star}$ at these same pressures suggests that it is formed directly in the ablation event, or in the plasma formed directly above the surface. The reaction of ground state yttrium atoms with molecular oxygen is shown to be the dominant mechanism for production of YO*. Quenching of the emission by molecular oxygen is shown to be significant at pressures above $\approx 10^{-1}$ torr.

\section{REFERENCES}

1. J. T. Cheung and H. Sankur. CRC Crit. Rev. Sol. St. Mat. Sci. , 15, 63-109 (1988).

2. H. Sankur and J. T. Cheung. Appl. Phys. A, A47, 271-284 (1988).

3. T. Venkatesan, Xindi Wu, Arun Inam, Chuan C. Chang, Manjanain S. Hegde and Barundeb Dutta. loe日 J. Quantum Electron. 25, 2388-93 (1989).

4. J. Narayan, N. Biunno, R. Singh, O. W. Holland and O. Auciello. Appl. Phys. Lett., 51, 1845-7 (1987).

5. C. C. Chang, X. D. Wu, A. Inam, D. M. Hwang, T. Venkatesan, P. Barboux and J. M. Tarascon. Appl. Phys. Lett. , 53, 517-19 (1988).

6. R. E. Muenchausen, K. M. Hubbard, S. Foltyn, C. Jenkins, R. C. Estler and N. S. Nogar. Appl. Phys. Lett. , 56, 578 (1990).

7. X. D. Wu, et al. Appl. Phys. Lett. , 56, 1481-3 (1990).

8. X. D. Wu, et al. Appl. Phys. Lett. , 57, 523-525 (1990).

9. R. C. Estler and N. S. Nogar. J. Appl. Phys. , in press, (1990).

10. R. C. Dye, R. E. Muenchausen and N. S. Nogar. Chem. Phys. Lett. , submitted, (1991).

11. D. M. Manos and J. M. Parson, J. Chem. Phys, 63, 3575 (1975); ibid, 69, 231 (1978).

12. C. L. Chalek and J. L. Gole, Chem. Phys. 19, 59 (1977); ibid, J. Chem. Phys., 65, 2845 (1976).

13. T. Wijchers, H. A. Dijkerman, P. J. Th. Zeegers and C. Th. J. Alkemade, Chem. Phys. 91, 141 (1984). 


